\title{
Exclusive breastfeeding and maternal employment among mothers of infants from three to five months old in the Fafan zone, Somali regional state of Ethiopia: a comparative cross-sectional study
}

\author{
Frew Tadesse ${ }^{1 *}$ (D) Yonas Alemayehu², Sisay Shine ${ }^{1}$, Henok Asresahegn ${ }^{1}$ and Trhas Tadesse ${ }^{3}$
}

\begin{abstract}
Background: Lack of exclusive breastfeeding is the most important risk factor for infant and young child morbidity and mortality. A better understanding of the factors that influence EBF is important in order to promote appropriate infant feeding practices. The return to work due to short maternity leave time may hinder employed mothers from breastfeeding their infants exclusively for the recommended six months duration.

Methods: A community based comparative cross-sectional study was conducted from January to February 2016 in the Fafan zone, of the Somali Regional State, of Ethiopia. A total of 558 mothers with infants from ages 3-5 months, living in the five districts (Jigjiga city, Kebribeyah town, Aubere town, Bombas town and Babile) were included in the analysis. Logistic regression models were used to examine the effect of maternal employment on EBF practice.

Results: This study has demonstrated a 24.8 and $82.9 \%$ prevalence of EBF practices among employed and unemployed mothers of index infants of 3-5 months respectively in the $24 \mathrm{~h}$ preceding the survey. Unemployed mothers were accounted for thusly: [Adjusted $\mathrm{OR}=26.5 ; 95 \% \mathrm{Cl}(13.6,51.6)$. Other adjustments included monthly income of 500-2000 birr [Adjusted $\mathrm{OR}=2.7 ; 95 \% \mathrm{Cl}(1.4,5.2)$ ]; monthly income of 2001-3500 birr [Adjusted OR= 2.2; $95 \% \mathrm{Cl}(1.2,4.0)]$; timely initiation of breastfeeding [Adjusted $\mathrm{OR}=2.6 ; 95 \% \mathrm{Cl}(1.4,4.8)]$; maternal education (secondary and higher) [Adjusted $\mathrm{OR}=3.8 ; 95 \% \mathrm{Cl}(1.5,9.5)$ ]; having an index infant aged 3 months [Adjusted OR= $2.2 ; 95 \% \mathrm{Cl}(1.2,4.1)$ ], and having an index infant aged 4 months [Adjusted $\mathrm{OR}=2.2 ; 95 \% \mathrm{Cl}(1.2,3.8)$ ] were found to be significantly associated with exclusive breastfeeding practice.

Conclusion: Exclusive breastfeeding practices were very low among mothers employed in governmental and nongovernmental organizations in the study area. Therefore, maternal employment may be hindering Exclusive breastfeeding practices. Thus, establishing breastfeeding-friendly working environment; and Information, Education and Communication programs should be provided, particularly for working mothers to promote exclusive breastfeeding practices.
\end{abstract}

Keywords: Exclusive breastfeeding, Maternal employment, Somali, Ethiopia

\footnotetext{
* Correspondence: fretaabrish@gmail.com

'Department of Public Health Officer, College of Medicine and Health

Sciences, Jigjiga University, Jigjiga, Ethiopia

Full list of author information is available at the end of the article
}

(c) The Author(s). 2019 Open Access This article is distributed under the terms of the Creative Commons Attribution 4.0 International License (http://creativecommons.org/licenses/by/4.0/), which permits unrestricted use, distribution, and reproduction in any medium, provided you give appropriate credit to the original author(s) and the source, provide a link to the Creative Commons license, and indicate if changes were made. The Creative Commons Public Domain Dedication waiver (http://creativecommons.org/publicdomain/zero/1.0/) applies to the data made available in this article, unless otherwise stated. 


\section{Background}

As per the definition of World Health Organization (WHO), exclusive breastfeeding (EBF) is defined as an infant's consumption of breast milk without supplementation of any other food or drink, not even water except for oral rehydration salt (ORS), vitamins, minerals, and medications. Infants should receive EBF for the first six months of life [1]. Lack of EBF is the most important risk factors for infant and young child morbidity and mortality including life-long impact like poor school performance, reduced productivity, and impaired intellectual development $[2,3]$. To reduce infant and young child mortality, EBF has been identified as one of the major cost-effective interventions worldwide [4-6]. In developing countries like Ethiopia, appropriate practice of EBF can avert 13\% of under-five mortality [6]. Despite its proven benefits, the proportion of exclusively breastfed children up to 6 months is lower than the optimal recommendations [7-11]. Studies conducted in different parts of the country [12-14] indicate that more than $80 \%$ of mothers are knowledgeable about EBF. Nevertheless, only $52 \%$ of children under age 6 months are exclusively breastfed, and the percentage of EBF declines with age from $70 \%$ in $0-1$ months to $32 \%$ in $4-5$ months. The median duration of EBF is low among the pastoralist and semi pastoralist communities of the country. In particular, the Somali region had the lowest median duration of EBF which is 0.5 months [10].

Sustainable Development Goal 2 (SDG 2) targets include ending hunger especially amongst the vulnerable and the poor and ending all forms of nutrition especially stunting and wasting of children under the age of five years [15]. Hence, a better understanding of the factors that influence EBF is necessary to promote appropriate infant feeding practices and attain SDG 2. In developing countries like Ethiopia, various maternal and child factors including maternal employment have been responsible for the low prevalence of EBF [7, 8, 14, 16-19]. In this study, being an employed mother has been hypothesized as one of the main barriers to EBF. Because of increasing urbanization and level of education, the proportion of employed women in Ethiopia has been increasing gradually [10]. Employed women in the formal and informal sectors face challenges combining work with breastfeeding. The return to work due to short maternity leave time may influence employed mothers not to start breastfeeding at all or discontinue EBF earlier than the recommended duration [20-23]. A research conducted in other part of the country [16] demonstrated that employed mothers were less likely to exclusively breastfeed their infant(s) than unemployed mothers. Although several studies have been conducted on the factors that are associated with EBF, there has been insufficient information regarding the effects of maternal employment in the formal sector on EBF practices in the semi-pastoralist community of the country specifically. Therefore, this study is intended to bridge this gap by assessing association maternal employment and EBF practices among mothers with infants between the ages of 3-5 months. The findings of this study will be crucial to the implementation interventions that speed up the government efforts in promoting EBF, and thereby decrease the rates and burden of infant morbidity and mortality.

\section{Methods \\ Study setting and population}

This study was conducted from January to February 2016 among mothers with infants between the ages of 3-5 months, living in the Fafan zone, of the Somali Regional State, of Ethiopia. The Fafan zone, which contains the capital of the Somali Regional state (Jigjiga), is a semi pastoralist community located at the Eastern border of the country. Here there are many rural and urban migrants that are attracted by trading and employment opportunities. Primary employers include governmental, and non-governmental organizations NGOs). These assertions are based on the 2007 Census conducted by Central Statistical Agency of Ethiopia. This zone has a total population of 967,652 , of which 526,398 are men and 441,254 women. About $12 \%$ of the 203,588 urban inhabitants were pastoralists [24].

The study participants were both employed, and unemployed mothers with infants from ages 3-5 months, living in the five districts (Jigjiga city, Kebribeyah town, Aubere town, Bombas town and Babile town) of the zone. Mothers, who were deaf, or critically ill, as well as mothers whose index infant had developmental delay were excluded from the study.

\section{Study design and data collection}

The study design was a comparative cross-sectional study. Quantitative data were collected by face-to face interview technique, using pre-tested structured questionnaires, adapted from the Ethiopian Health and Demographic Survey (EDHS) 2011, and WHO [10, 25]. The questionnaire contained questions on infant characteristics (age and sex), maternal demographic characteristics (age, occupation, income, education and marital status) breastfeeding knowledge, obstetric characteristics, and EBF practices. It was initially contextualized and prepared in English and then translated into "Somaligna" and "Amharic", and it was translated back into English to check its consistency.

Census was conducted in each study areas before the actual data collection to determine the total number of mothers of index infants of 3-5 months. A total of 583 mothers of index infants ages 3-5 months (122 
employed and 461 unemployed mothers) were recruited by census. Trained Health Extension Workers and diploma nurses administered the questionnaire after obtaining informed consent from the respondents. To ensure the quality of the data, the questionnaire was pre-tested in a purposively selected town that has not been selected for the study. Data was manually checked and coded for completeness, consistency and validity by supervisors and principal investigators.

In this study, the outcome variable was the status of EBF of infants three to five months of age. EBF was defined as feeding only breast milk (including milk expressed or from a wet nurse) without anything else in the last $24 \mathrm{~h}$ preceding the interview except for ORS, drops, and syrups (vitamins, minerals, medicines) for therapeutic purposes [26]. Regarding the employment status of mothers, only those who were actively working full time in either governmental organization or NGOs by the time of data collection were considered as employed mothers, while mothers who were housewives (without a job) were considered as unemployed in our study. Mothers who received either institutional support, or extended maternity or leave were excluded from the study. Mothers who were working in private businesses such as merchants were also excluded from the study for two main reasons: First, there is no formal maternal leave in this type of employment. Secondly, mothers might get the chance to bring their infant with them to work site to breastfeed. The aforementioned reasons above may underestimate the effect of maternal employment on EBF practices. Additionally, early initiation of breastfeeding was defined as initiation of breastfeeding within one hour of birth of the neonate.

\section{Statistical analysis}

Data entry was made using EPI INFO version 3.5.1 software package and analyzed using SPSS version 16 . A binary logistic regression model with enter logistic regression analysis method was utilized to examine the effect of maternal employment on EBF. Variables with $p$-value of less than 0.2 in the bivariate analyses were entered multivariate logistic regression model. Crude and adjusted odds ratios are presented with a 95\% confidence interval to measure the strength of association. Variables with $\mathrm{p}$-value of $<0.05$ were declared statistically significant. Model fitness was tested by using the Hosmer-Lemeshow goodness-of-fit and Omnibus tests of model coefficients tests with enter procedure. By using the Variance Inflation Factor (VIF) test, the Tolerance test, and values of the standard error; the explanatory variables were tested for multicollinearity before entering them into the multivariable model.

\section{Results}

Characteristics of the study participants

Among the total 583 mother-infant pairs recruited by census, 558 were included in the analysis. Thus, the response rate was $95.7 \%$ and the remaining $4.3 \%$ were excluded from the analysis due to incompleteness, and inconsistencies.

A total of 445 (79.7\%) unemployed and 113 (20.3\%) employed mothers of index infants of 3-5 months participated in the study. The mean and median ages of the mothers were 25.64 and 25.49 years old respectively for employed mothers, and 25 years old for unemployed mothers. Sixty $(53.1 \%)$ of the respondents were Muslim and $160(39.4 \%)$ were Christian among the employed mothers while $319(71.7 \%)$ of the respondents were Muslim and 126 (28.3\%) were Christian among the unemployed mothers. Majority, 88.5 and $92.1 \%$ were married in union, among the employed and unemployed mothers respectively. Regarding the educational status of the mothers; 76 (67.3\%) secondary and higher, followed by primary school 19 (16.8\%), informal education 14 (12.4\%), and illiterate $4(3.5 \%)$ among those employed mothers. Whereas, among the unemployed mothers; 162 (36.4\%) primary school, followed by 117 (26.3\%) secondary and higher, $92(20.7 \%)$ illiterate, and 74 (16.6\%) informal education. The average household income was $3632.43 \quad(\mathrm{SD} \pm 148.45)$ and 2873.24 $(\mathrm{SD} \pm 82.99)$ Ethiopian Birr per month, among the employed and unemployed mothers respectively (Table 1).

\section{Breastfeeding knowledge and obstetric characteristics}

The entire employed and unemployed mothers supported the importance of breast feeding for infant's health. Majority, 80 (70.8\%) of employed and 308 (69.2\%) of unemployed mothers supported the importance of breastfeeding for maternal health respectively. Almost all of the respondents, 112 (99.1\%) of employed and $440(98.9 \%)$ of unemployed mothers said breast milk is better than infant formula. Most of mothers, 90 (79.6\%) of employed and 341 (76.6\%) of unemployed mothers were aware of the recommended six months duration of Exclusive Breastfeeding respectively. On the other hand, 105 (92.9\%) of employed and 396 (89.0\%) of unemployed mothers visited the health facility at least once during their pregnancy with mean number of ANC visits of $3.9(\mathrm{SD} \pm 0.2)$ and $3.9(\mathrm{SD} \pm 0.1)$ respectively. Regarding to information about EBF, 154 (81\%) of employed and 166 (69\%) of unemployed mothers were informed about EBF respectively (Table 2).

\section{Exclusive breastfeeding practices}

The study revealed that the prevalence of EBF practices was 24.8 and $82.9 \%$ among employed and unemployed mothers respectively in the $24 \mathrm{~h}$ preceding the survey. 
Table 1 Socio-demographic characteristics of the study participants

\begin{tabular}{|c|c|c|c|}
\hline \multirow[t]{2}{*}{ Variables } & \multicolumn{2}{|c|}{ Maternal employment } & \multirow[b]{2}{*}{$P$ value* } \\
\hline & $\begin{array}{l}\text { Employed } \\
N(\%)\end{array}$ & $\begin{array}{l}\text { Unemployed } \\
N(\%)\end{array}$ & \\
\hline \multicolumn{4}{|l|}{ Maternal Age } \\
\hline $17-19$ & $3(2.7)$ & $36(8.1)$ & \multirow[t]{4}{*}{0.049} \\
\hline $20-24$ & $37(32.7)$ & $146(32.8)$ & \\
\hline $25-29$ & $53(46.9)$ & $160(36.0)$ & \\
\hline$\geq 30$ & $20(17.7)$ & $103(23.1)$ & \\
\hline \multicolumn{4}{|l|}{ Maternal Education } \\
\hline Illiterate & $4(3.5)$ & $92(20.7)$ & \multirow[t]{4}{*}{0.000} \\
\hline Informal education & $14(12.4)$ & $74(16.6)$ & \\
\hline Primary & 19 (16.8) & $162(36.4)$ & \\
\hline Secondary and higher & $76(67.3)$ & $117(26.3)$ & \\
\hline \multicolumn{4}{|l|}{ Ethnicity } \\
\hline Somali & $44(38.9)$ & $226(50.8)$ & \multirow[t]{2}{*}{0.024} \\
\hline Others & $69(61.1)$ & $219(49.2)$ & \\
\hline \multicolumn{4}{|l|}{ Religion } \\
\hline Muslim & $60(53.1)$ & $319(71.7)$ & \multirow[t]{2}{*}{0.000} \\
\hline Christian & $53(46.9)$ & $126(28.3)$ & \\
\hline \multicolumn{4}{|l|}{ Age of Infant } \\
\hline 3 months & 21 (18.6) & $126(28.3)$ & \multirow[t]{3}{*}{0.012} \\
\hline 4 months & $30(26.5)$ & $142(31.9)$ & \\
\hline 5 months & $62(54.9)$ & $177(39.8)$ & \\
\hline \multicolumn{4}{|l|}{ Sex of Infant } \\
\hline Male & $57(50.4)$ & $212(47.6)$ & \multirow[t]{2}{*}{0.594} \\
\hline Female & $56(49.6)$ & $233(52.4)$ & \\
\hline \multicolumn{4}{|l|}{ Husband education } \\
\hline Illiterate & $4(3.7)$ & $25(5.7)$ & \multirow[t]{4}{*}{0.569} \\
\hline Informal education & $7(6.4)$ & $42(9.6)$ & \\
\hline Primary & $16(14.7)$ & $65(14.8)$ & \\
\hline Secondary and higher & $82(75.2)$ & $306(69.9)$ & \\
\hline \multicolumn{4}{|l|}{ Husband Occupation } \\
\hline Farmer/Pastoralist & $20(18.3)$ & $81(18.5)$ & \multirow[t]{5}{*}{0.092} \\
\hline Daily laborer & $11(10.1)$ & $76(17.4)$ & \\
\hline Government Employee & $35(32.1)$ & $94(21.5)$ & \\
\hline NGO Employee & $10(9.2)$ & $33(7.5)$ & \\
\hline Merchant & $33(30.3)$ & $154(35.2)$ & \\
\hline \multicolumn{4}{|c|}{ Average family income (in Birr) } \\
\hline $500-2000$ & $20(18.0)$ & $183(43.0)$ & \multirow[t]{3}{*}{0.000} \\
\hline $2001-3500$ & $42(37.8)$ & 139 (32.6) & \\
\hline $3501-10000$ & $49(44.1)$ & $104(24.4)$ & \\
\hline
\end{tabular}

On the one hand, being engaged at work place 68 $(81.9 \%)$, the perception that breast milk only is not enough 8 (9.6\%), and decreased milk secretion 4 (4.8\%), as well as illness of the mother $3(3.6 \%)$ were the reasons
Table 2 Breastfeeding knowledge and obstetric characteristics among the study participants

\begin{tabular}{|c|c|c|c|}
\hline \multirow[b]{2}{*}{ Variables } & \multicolumn{2}{|c|}{ Maternal Employment } & \multirow[b]{2}{*}{$P$ value* } \\
\hline & $\begin{array}{l}\text { Employed } \\
\text { N (\%) }\end{array}$ & $\begin{array}{l}\text { Unemployed } \\
\text { N (\%) }\end{array}$ & \\
\hline \multicolumn{4}{|c|}{ Breastfeeding is important for maternal health } \\
\hline Yes & $80(70.8)$ & $308(69.2)$ & 0.073 \\
\hline No & $16(14.2)$ & $38(8.5)$ & \\
\hline Don't know & $17(15.0)$ & $99(22.2)$ & \\
\hline \multicolumn{4}{|c|}{ Infant should be put to breast immediately after birth } \\
\hline Yes & $104(92.0)$ & $395(88.8)$ & 0.480 \\
\hline No & $1(0.9)$ & $11(2.5)$ & \\
\hline Don't know & $8(7.1)$ & $39(8.8)$ & \\
\hline \multicolumn{4}{|c|}{ Breast milk is better than infant formula } \\
\hline Yes & $112(99.1)$ & $440(98.9)$ & 0.754 \\
\hline No & $0(0.0)$ & $2(0.4)$ & \\
\hline Don't know & $1(0.9)$ & $3(0.7)$ & \\
\hline \multicolumn{4}{|l|}{ Perceived Duration of EBF } \\
\hline Six months & $90(79.6)$ & $341(76.6)$ & 0.782 \\
\hline Other than six months & $21(18.6)$ & 96 (21.6) & \\
\hline Don't know & $2(1.8)$ & $8(1.8)$ & \\
\hline \multicolumn{4}{|l|}{ ANC attended } \\
\hline Yes & $105(92.9)$ & $396(89.0)$ & 0.218 \\
\hline No & $8(7.1)$ & $49(11.0)$ & \\
\hline \multicolumn{4}{|l|}{ Place of delivery } \\
\hline Health facility & $101(89.4)$ & $397(89.2)$ & 0.959 \\
\hline Home & $12(10.6)$ & $48(10.8)$ & \\
\hline \multicolumn{4}{|l|}{ Mode of delivery } \\
\hline Vaginal & $104(92.0)$ & $425(95.5)$ & 0.138 \\
\hline Caesarean section & $9(8.0)$ & $20(4.5)$ & \\
\hline
\end{tabular}

stated by the employed mothers for feeding their infant something other than breast milk in the past $24 \mathrm{~h}$. On the other hand, the perception that breast milk only is not enough 35 (45.5\%), decreased milk secretion 34 (44.2\%), and illness of the mother 8 (10.4\%) were the reasons stated by the unemployed mothers for feeding their infant something other than breast milk in the past $24 \mathrm{~h}$. Regarding to complementary feeding, 68 (60.2\%) and $42(9.4 \%)$ infant formula, $12(10.6 \%)$ and $19(4.3 \%)$ plain water or with additives, $21(18.6 \%)$ and $10(2.2 \%)$ semisolids, $21(18.6 \%)$ and 9 (2.0\%) cow milk, among employed and unemployed mothers respectively in the $24 \mathrm{~h}$ prior to the survey (Table 3 ).

\section{Factors associated with EBF}

In the bivariate analysis, being an unemployed mother, younger age of the infant, timely initiation of breastfeeding, having positive attitude towards breastfeeding an 
Table 3 Exclusive breastfeeding practices among the study participants

\begin{tabular}{llll}
\hline Variables & \multicolumn{2}{c}{ Maternal Employment } & \\
\cline { 2 - 3 } & $\begin{array}{l}\text { Employed } \\
\text { N (\%) }\end{array}$ & $\begin{array}{l}\text { Unemployed } \\
\text { N (\%) }\end{array}$ & \\
\hline Timely initiation of breastfeeding & & \\
Yes & $95(84.1)$ & $382(85.8)$ & 0.633 \\
No & $18(15.9)$ & $63(14.2)$ & \\
Pre-lactal feeding & & & \\
Yes & $13(11.5)$ & $41(9.2)$ & 0.462 \\
No & $100(88.5)$ & $404(90.8)$ & \\
EBF status & & & \\
Exclusively Breastfed & $28(24.8)$ & $369(82.9)$ & 0.000 \\
Non-Exclusively Breastfed & $85(75.2)$ & $76(17.1)$ & \\
Reason for Non-exclusive Breast feeding & & \\
Decreased milk secretion & $4(4.8)$ & $34(44.2)$ & 0.000 \\
Only Breast milk not enough & $10(9.6)$ & $35(45.5)$ & \\
Was at work place & $68(81.9)$ & $0(0.0)$ & \\
IIlness of mother & $3(3.6)$ & $8(10.4)$ & \\
\hline
\end{tabular}

infant in a public place, and delivering at a health facility were significantly associated with EBF. Controlling for other variables, being an unemployed mother, monthly income, timely initiation of breastfeeding, and younger age of infant were significantly associated with EBF in the multivariate logistic regression model for the overall study participants.

Among all, those mothers who were unemployed were twenty six times more likely to practice EBF compared to those employed mothers [Adjusted OR = 26.5 ; 95\% CI $(13.6,51.6)]$; mothers with monthly income of 500-2000, and 2001-3500 birr were twice as likely to practice EBF compared to those with above 3501 birr monthly income [Adjusted OR $=2.7 ; 95 \%$ CI $(1.4,5.2)$ ]; and [Adjusted OR $=2.2$; $95 \%$ CI $(1.2,4.0)$ ] respectively; mothers who completed secondary and higher education were about four times more likely to practice EBF compared to those who were illiterate [Adjusted OR $=3.8 ; 95 \%$ CI $(1.5,9.5)$ ]; those who initiated breastfeeding within one hour of delivery were about three times more likely to practice EBF compared to their counterparts [Adjusted $\mathrm{OR}=2.6$; 95\% CI $(1.4,4.8)]$; mothers of 3 months and 4 months age infants were about three times more likely to practice EBF compared to those mothers of 5 months age infants [Adjusted OR $=2.2 ; 95 \%$ CI $(1.2,4.1)$ ], and [Adjusted $\mathrm{OR}=2.2 ; 95 \%$ CI $(1.2,3.8)$ ] respectively. The other variables were not significantly associated with EBF practice after adjusting for confounders (Table 4).

\section{Discussion}

This study provides information regarding the effect of maternal employment on EBF among mothers of index infants of 3-5 months, living in the Semi-pastoralist community of Eastern border of Ethiopia where many governmental and non-governmental organizations are located. This study has demonstrated a prevalence of 24.8 and $82.9 \%$ of EBF practices among employed and unemployed mothers of index infants of 3-5 months respectively in the $24 \mathrm{~h}$ preceding the survey. Being an unemployed mother, timely initiation of breastfeeding, and younger age of infant were significantly associated with EBF.

The prevalence of EBF in our study was low among employed and high among unemployed mothers, which is in line with studies conducted in different parts of Ethiopia [7, 8, 16]. In a similar trade, unemployed mothers were twenty-five times more likely to exclusively breastfeed their infants as compared to those employed mothers. This indicates that maternal employment is a hindrance for EBF. In agreement with this, studies from Ethiopia [7, 8, 16, 17, 27], peninsular Malaysia [18, 28], Saudi Arabia [29, 30], and Canada [31] reported that maternal employment has a negative effect on EBF. Many reasons can be stated for this association. In accordance with the Constitution of Ethiopia and Labor Proclamation, female workers are entitled to fully paid maternity leave of 90 days (30 days antenatal and 60 days postnatal) on recommendation of medical doctor. Hence employed mothers will have a maximum of two or three months to stay at home and breastfed their infants which doesn't fit with the recommended six months of EBF. This short maternity leave period successively influences them to introduce complementary feeding starting from the time they return to work [21, 32]. Another study [33] reported that, each week of maternity leave increased the duration of breastfeeding by almost one-half week. Besides, since there is no breastfeeding friendly environment like facilities for breastfeeding at workplaces, employed mothers couldn't take their infants to the workplace and breastfeed there [21,34]. Therefore, the summative effect of the stated reasons above, would compromise the rate of EBF among employed mothers. To the contrary, some other studies $[35,36]$ have reported that maternal employment has no effect on EBF.

In this study, mothers with a lower monthly household income had high tendency to practice EBF. This agrees with findings from Ethiopia [37] and South Africa [38]. This could be explained by the reason that breastfeeding is the only option for mothers with lower monthly income as they cannot afford to buy other alternative foods. Nevertheless, it is difficult to conclude since 
Table 4 Factors associated with exclusive breastfeeding practices

\begin{tabular}{|c|c|c|c|c|}
\hline Variables & Non-EBF & EBF & Crude OR (95\% Cl) & Adj. OR (95\% Cl) \\
\hline \multicolumn{5}{|l|}{ Maternal Employment } \\
\hline Employed & 85 & 28 & 1 & 1 \\
\hline Unemployed & 76 & 369 & $14.7(9.0,24.1)^{* *}$ & $26.5(13.6,51.6)^{* *}$ \\
\hline \multicolumn{5}{|l|}{ Maternal Education } \\
\hline Illiterate & 27 & 69 & 1 & 1 \\
\hline Informal education & 28 & 60 & $0.8(0.5,1.6)$ & $1.1(0.5,2.4)$ \\
\hline Primary & 39 & 142 & $1.4(0.8,2.5)$ & $1.9(0.9,3.9)$ \\
\hline Secondary and higher & 67 & 126 & $0.7(0.4,1.3)$ & $3.8(1.5,9.5)^{*}$ \\
\hline \multicolumn{5}{|l|}{ Age of Infant } \\
\hline 3 months & 27 & 120 & $3.1(1.9,5.1)^{* *}$ & $2.2(1.2,4.1)^{*}$ \\
\hline 4 months & 36 & 136 & $2.6(1.7,4.1)^{* *}$ & $2.2(1.2,3.8)^{*}$ \\
\hline 5 months & 98 & 141 & 1 & 1 \\
\hline \multicolumn{5}{|c|}{ An infant should be put to breast immediately after birth? } \\
\hline Yes & 139 & 360 & $1.5(0.9,2.7)$ & $1.4(0.7,3.0)$ \\
\hline No & 22 & 37 & 1 & 1 \\
\hline \multicolumn{5}{|l|}{ Place of delivery } \\
\hline Health facility & 137 & 361 & $1.8(1.0,3.1)$ & $1.0(0.5,2.2)$ \\
\hline Home & 24 & 36 & 1 & 1 \\
\hline \multicolumn{5}{|c|}{ Timely initiation of breast feeding } \\
\hline Yes & 123 & 354 & $2.5(1.6,4.1)^{* *}$ & $2.6(1.4,4.8)^{*}$ \\
\hline No & 38 & 43 & 1 & 1 \\
\hline \multicolumn{5}{|c|}{ Mother received information/advice on BF } \\
\hline Yes & 85 & 204 & 1 & 1 \\
\hline No & 76 & 193 & $0.9(0.7,1.4)$ & $1.4(0.8,2.5)$ \\
\hline \multicolumn{5}{|l|}{ History of breast disease } \\
\hline Yes & 26 & 42 & 1 & 1 \\
\hline No & 135 & 355 & $1.6(0.9,2.8)$ & $1.9(0.9,3.6)$ \\
\hline \multicolumn{5}{|c|}{ Breastfeeding at public place is wrong } \\
\hline True & 88 & 167 & 1 & 1 \\
\hline False & 73 & 230 & $1.7(1.2,2.4)^{*}$ & $1.5(0.9,2.6)$ \\
\hline \multicolumn{5}{|l|}{ Husband support } \\
\hline Yes & 113 & 252 & $0.7(0.4,1.0)$ & $0.7(0.4,1.2)$ \\
\hline No & 42 & 140 & 1 & 1 \\
\hline \multicolumn{5}{|c|}{ Average family income (in Birr) } \\
\hline $500-2000$ & 41 & 162 & $4.3(2.4,7.7)^{* *}$ & $2.7(1.4,5.2)^{*}$ \\
\hline $2001-3500$ & 51 & 130 & $1.6(0.9,2.5)$ & $2.2(1.2,4.0)^{*}$ \\
\hline $3501-10000$ & 65 & 88 & 1 & 1 \\
\hline
\end{tabular}

*- Significance level of $<0.05 *$ * Significance level of $<0.001$

monthly household income is not enough of an indicator of socioeconomic status; rather wealth index should have been done to determine this variable. Hence, this can be quoted as a limitation of the present study. On the other hand, mothers whose educational status was secondary or higher were more likely to practice EBF in the present study. This is in line with the research findings from Ethiopia [35], United Arab Emirates [39], and India [40]. The possible explanation for this association could be the fact that educated mothers may have a better knowledge regarding child feeding practices as they are prone to get information from different channels. Early initiation of breastfeeding was positively associated with EBF practice. This is in accordance with findings 
from Ethiopia, China and Egypt [9, 16, 35, 41, 42]. This could be due to the fact that early suckling stimulates the release of prolactin, which helps in the production of milk, and is responsible for the ejection of milk $[3,9,10]$. Hence, if there is delayed initiation of breastfeeding, the production of breast milk would be inhibited due to limited stimulation of the neonate to suckle, as a result to the initiation of pre-lactal foods.

This study revealed that child's age had significant association with EBF practice. Infants in age group of 3 and 4 months were three times more likely to receive EBF as compared to those whose age was 5 months. This finding was consistent with the studies conducted in other parts of Ethiopia [7, 8, 35, 43], Nigeria [44], and Uganda [45]. Different studies indicate that the rate of EBF decreases significantly as the age of infants come close to 6 months in Iran, Uganda, Sudan, and Ethiopia $[8,43,45-47]$. The first possible reason for this association could be the traditional postpartum rest in the first few months after delivery that obligates women to stay at home. This, as a result may encourage them to breastfeed their infant. The other explanation may be due to the perception that some mothers have, that breast milk alone is not enough as the infant gets older [7, 8].

The present study has its own strengths and limitations. We only included mothers of index infants of 3-5 months to determine the real effect of maternal employment on EBF practices, as employed mothers with infants aged less than 3 months couldn't be hindered by their employment since they would be on maternity leave. The use of comparison group in our study has boosted its ability to draw inferential causalities between the independent variables and the practice of EBF. In ascertaining EBF, we used the 24-h recall method to determine EBF which currently is recommended by WHO. Hence, we minimized the recall bias in ascertaining EBF that could have occurred by the other methods. Nevertheless, there are some limitations inherent to this method. As per the report of many studies [48-52], since the single $24 \mathrm{~h}$ recall only captures a single glance, it may not represent the usual intake of an infant if there is a day to day variation in the feeding pattern, which may consequently lead to an overestimation and misclassification. In addition, there might be a recall bias in ascertaining some variables like early initiation of breastfeeding and other maternal health care related variables. We included only government and NGO full time workers since there is no formal maternity leave in the other employment types such as traders. For that reason, this study doesn't represent all employed mothers.

\section{Conclusions}

In conclusion, the prevalence of EBF practices in the study area was very low among mothers employed in governmental and NGOs but high among unemployed mothers, indicating a significant difference between the two groups. Hence, maternal employment in governmental organizations or NGOs may have a negative influence on EBF practices. In addition, early initiation of breastfeeding, low income, maternal education and younger infant age, were also significantly associated with EBF practice. In developing countries like Ethiopia where the rate of urbanization increases through time, the tendency of women to be educated and employed would be high. In effect, this reduces the chance of their infants to be exclusively breastfed, and in turn increases under-five mortality due to infant malnutrition. Thus, we recommend that breastfeeding-friendly work environment should be launched for working mothers by establishing work-site day care centers for infants in order to promote of EBF. Moreover, Information, Education and Communication (IEC) programs on EBF practices should be provided mainly for employed mothers with a special focus on timely initiation of breastfeeding. Further analytical studies, especially follow-up studies, in big cities of the country where there is a high proportion of employed mothers is suggested to explore the effect of maternal employment on EBF practices.

\section{Abbreviations}

EBF: Exclusive Breastfeeding; EDHS: Ethiopian Health and Demographic Survey; IEC: Information, Education and Communication; NGO: NonGovernmental Organization; ORS: Oral Rehydration Salt; SDG 2: Sustainable Development Goal 2; WHO: World Health Organization

\section{Acknowledgements}

Our heartfelt thanks go to the Jigjiga University for funding this research without which it would not have been materialized. We would also like to thank Somali Health Bureau and all the Kebele administrative of Jigjiga, Bombas, Kebribeya, Aubere and Babile for allowing us to carry out this study. Above all, we are grateful to the data collectors, supervisors and study participants for their full cooperation during data collection.

\section{Authors' contributions}

FT was conceived the study and involved in proposal writing, designed the study and participated in coordination, supervision and the overall implementation of the project, analyzed the data, drafted and finalized the manuscript. YA, SS, HA and TT participated in all stages of the study and revision of the manuscript. FT obtained funding for the study. All authors read and approved the final version of the manuscript.

\section{Funding}

This work was funded by the Jigjiga University. The sponsors of the study had no role in study design, data collection, data analysis, data interpretation, or writing of the report. The corresponding author had full access to the data in the study and had full responsibility for the decision to submit.

\section{Availability of data and materials}

The datasets generated during and/or analyzed during the current study are available from the corresponding author on reasonable request.

\section{Ethics approval and consent to participate}

The study protocol was reviewed and approved by the research and publication technology transfer committee of Jigjiga University which had the authority to approve ethics for scientific study. Written informed consent was obtained from each participant (mother of the infant) and confidentiality was maintained. Lastly, information and education were given to the study subjects regarding EBF. 


\section{Competing interests}

The authors have declared that there are no competing interests.

\section{Author details}

'Department of Public Health Officer, College of Medicine and Health Sciences, Jigjiga University, Jigjiga, Ethiopia. ${ }^{2}$ Department of Nursing, College of Medicine and Health Sciences, Jigjiga University, Jigjiga, Ethiopia. ${ }^{3}$ Department of Social and Population Health, Yekatit 12 Hospital Medical College, Addis Ababa, Ethiopia.

\section{Received: 11 April 2019 Accepted: 19 July 2019} Published online: 29 July 2019

\section{References}

1. WHO, UNICEF: Indicators for assessing infant and young child feeding practices PART 3 country profiles: WHO press, world health organization, 20 Avenue Appia, 1211 Geneva 27, Switzerland [internet]; 2010. [cited 20110ct 3]; Available from: http://whqlibdoc.who.int/publications/2010/9789241599757_ eng.pdf.

2. World Health Organization: Global strategy for infant and young child feeding. The optimal duration of exclusive breastfeeding. Geneva: World Health Organization; 2001.

3. World Health Organization. Infant and young child feeding (IYCF) model chapter for textbooks for medical students and allied health professionals. Switzerland: World Health Organization; 2009. Available from: https://www. ncbi.nlm.nih.gov/books/NBK148970/

4. WHO Collaborative Study Team on the Role of Breastfeeding on the Prevention of Infant Mortality. Effect of breastfeeding on infant and child mortality due to infectious diseases in less developed countries: a pooled analysis. Lancet. 2000;355:451-5.

5. Black RE, Allen LH, Bhutta ZA, Caulfield LE, de Onis M, Ezzati M, Mathers C, Rivera J. Maternal and child undernutrition: global and regional exposures and health consequences. Lancet. 2008;371:243-60.

6. Jones G, Steketee RW, Black RE, Bhutta ZA, Morris SS. Bellagio child survival study G: how many child deaths can we prevent this year? Lancet. 2003;362(9377):65-71.

7. Seid, et al. Prevalence of Exclusive Breastfeeding. Practices and associated factors among mothers in Bahir Dar city, Northwest Ethiopia: a community based cross-sectional study. Int Breastfeeding J. 2013;8:14. https://doi.org/1 0.1186/1746-4358-8-14

8. Setegn, et al. Factors associated with exclusive breastfeeding practices among mothers in Goba district, south east Ethiopia: a cross-sectional study. Int Breastfeed J. 2012;7:17. https://doi.org/10.1186/1746-4358-7-17.

9. Woldie TG, Kassa AW, Edris M. Assessment of Exclusive Breast-Feeding Practice and Associated Factors in Mecha District, North West Ethiopia. Sci J Public Health. Vol. 2, No. 4, 2014, pp. 330-336. https://doi.org/10.1164 8/j.sjph.20140204.24

10. Central Statistical Agency [Ethiopia] and ICF International. Ethiopia Demographic and Health Survey 2011. Addis Ababa, Ethiopia and Calverton, Maryland, USA; 2012

11. Girma W, Genebo T. Determinants of nutritional status of women and children in Ethiopia. ORC Macro: Calverton, Maryland, USA; 2002.

12. Wolde T, et al. Knowledge, attitude and practice of exclusive breastfeeding among lactating mothers in Bedelle town, Southwestern Ethiopia: Descriptive cross-sectional study. Researcher. 2014;6:11.

13. Begna Z, et al. Knowledge and practice of mothers towards exclusive breastfeeding and its associated factors in ambo Woreda west Shoa zone Oromia region. Ethiopia Int J Res Dev Pharm Life Sci. 2015;4:3.

14. Mitiku M, Damte M, Kebede Z. Factors associated with exclusive breastfeeding practices in Debre Berhan District, Central Ethiopia: a cross sectional community-based study. Int Breastfeed J. 2015;10:23.

15. United Nations. Sustainable Development Goals [Internet]. Sustainable Development Knowledge Platform. 2015 [cited 2016 Jan 4]. Available from: https://sustainabledevelopment.un.org/?menu=1300\#.

16. Taddele M, Abebe L, Fentahun N. Exclusive Breastfeeding and Maternal Employment in Ethiopia: A Comparative Cross- Sectional Study. Int J Nutr Food Sci. Vol. 3, No. 6, 2014, pp. 497-503. https://doi.org/10.11648/j.jjnfs.2 0140306.12

17. Arage $\mathrm{G}, \mathrm{Gedamu} \mathrm{H}$. Exclusive breastfeeding practice and its associated factors among mothers of infants less than six months of age in Debre
Tabor town, Northwest Ethiopia: A Cross-Sectional Study. Advances in Public Health. 2016.

18. Tan. Factors associated with exclusive breastfeeding among infants under six months of age in peninsular Malaysia. Int Breastfeeding J. 2011;6:2. https://doi.org/10.1186/1746-4358-6-2.

19. Mekuria G, Edris M. Exclusive breastfeeding and associated factors among mothers in Debre Markos, Northwest Ethiopia: a cross-sectional study. Int Breastfeed J. 2015;10:1.

20. Baker M, Milligan KS. Maternal employment, breast feeding, and health: Evidence from maternity leave mandates. University of Toronto, department of economics, Canada. 2007.

21. U.S. Department of Health and Human Services. The Surgeon General's Call to Action to Support Breastfeeding. Washington, DC: U.S. Department of Health and Human Services, Office of the Surgeon General; 2011. https:// www.hhs.gov/sites/default/files/breastfeeding-call-to-action-executivesummary.pdf.

22. Johnston ML, Esposito N. Barriers and facilitators for breastfeeding among working women in the United States. J Obstet Gynecol Neonatal Nurs. 2007;36:9-20.

23. Fein SB, Roe B. The effect of work status on initiation and duration of breast-feeding. Am J Public Health. 1998:88:1042-6.

24. CSA. The 2007 population and housing census of Ethiopia: Results for Somali Regional State. Addis Ababa. p. 2007.

25. WHO, UNICEF: Indicators for assessing infant and young child feeding practices part 2 measurement: WHO press, world health organization, 20 avenue Appia, 1211 Geneva 27, Switzerland; 2010.

26. WHO, UNICEF: Indicators for assessing infant and young child feeding practices Part 1 Definitions: conclusions of a consensus meeting held 6-8 November 2007 in Washington D.C., USA: WHO press, world health organization, 20 Avenue Appia, 1211 Geneva 27, Switzerland; 2010.

27. Yeneabat, et al. Determinants of cessation of exclusive breastfeeding in Ankesha Guagusa Woreda, Awi Zone, Northwest Ethiopia: a cross-sectional study. BMC Pregnancy and Childbirth. 2014;14:262

28. Tan KL. Factors associated with non-exclusive breastfeeding among 4-week post-partum mothers in Klang District, peninsular Malaysia. Mal J Nutr. 2009;15:11-8.

29. El-Gilany A-H, Shady E, Helal R. Exclusive breastfeeding in Al-Hassa, Saudi Arabia. Breastfeed Med. 2011;6(4):209-13.

30. El-Gilany A, El-Wehady A. Maternal work and infant health in Al-Hassa, Saudi Arabia. Paediatrs.me. 2007;12(4):100-5.

31. Al-Sahab B, Lanes A, Feldman M, Tamim H. Prevalence and predictors of 6-month exclusive breastfeeding among Canadian women: a national survey. BMC Pediatr. 2010;10:20.

32. Arthur CR, Saenz RB, Replogle WH. The employment related breastfeeding decisions of physician mothers. J Miss State Med Assoc. 2003:44:383-7.

33. Roe $B$, Whittington LA, Fein SB, Teisl MF. Is there competition between breastfeeding and maternal employment? Demography. 1999;36:157-71.

34. Brown CA, Poag S, Kasprzycki C. Exploring large employers' and small employers' knowledge, attitudes, and practices on breastfeeding support in the workplace. J Hum Lact. 2001:17:39-46.

35. Lenja A, Demissie T, Yohannes B, Yohannis M. Determinants of exclusive breastfeeding practice to infants aged less than six months in Offa district, Southern Ethiopia: a cross-sectional study. Int Breastfeeding J. 2016;11:32. https://doi.org/10.1186/s13006-016-0091-8.

36. Chudasama RK, Amin CD, Parikh YN. Prevalence of exclusive breastfeeding and its determinants in first 6 months of life: A prospective study. Online J Health Allied Sci. 2009:8(1) https://www.researchgate.net/ publication/26627173_Prevalence_of_exclusive_breastfeeding_and_its_ determinants_in_first_6_months_of_life_A_prospective_study (Accessed Sept 2010.

37. Tilahun T, Alemnesh M, Tenaw G, Girma A, Getnet M, Haymanot Z. Exclusive breastfeeding practice and associated factors among mothers in Motta town, east Gojjam zone, Amhara regional state, Ethiopia, 2015: a crosssectional study. Int Breastfeed J. 2017;12:12. https://doi.org/10.1186/s13006017-0103-3.

38. Sowden M, Marais D, Beukes R. Factors influencing high socio-economic class mothers' decision regarding formula-feeding practices in the cape metropole. S Afr J Clin Nutr. 2009;22(1):37-44. 
39. Radwan H. Patterns and determinants of breastfeeding and complementary feeding practices of Emirati mothers in the United Arab Emirates. BMC Public Health. 2013;13:171.

40. Aggobenija MD, Nidfe J. Evaluation of infant feeding practice and care practices among mothers in Nassarawa Eggon local goverment of Nassarawa state. Indian J Sci Res. 2012;3(1):21-9.

41. Leung TF, Tam WH, Hung E, Fok TF, Wong G. Sociodemographic and atopic factors affecting breastfeeding intention in Chinese mothers. J Pediatrics Child Health. 2003:39:460-4.

42. Ghwass A, Ahmed D. Prevalence and Predictors of 6-Month Exclusive Breastfeeding in a Rural Area in Egypt. Breastfeeding Med. 2011;6(4):191-6.

43. Alemayehu T, Haidar J, Habte D. Determinants of exclusive breastfeeding practices in Ethiopia. Ethiop J Health Dev. 2009;23(1):12-8.

44. Agho KE, Dibley MJ, Odiase Jl, Ogbonmwan SM. Determinants of exclusive breastfeeding in Nigeria. BMC Pregnancy Childbirth. 2011;1:2

45. Engebretsen IM, Wamani H, Karamagi C, Semiyaga N, Tumwine J, Tylleskär T. Low adherence to exclusive breastfeeding in eastern Uganda: a community-based cross-sectional study comparing dietary recall since birth with 24-hour recall. BMC Pediatr. 2007;7:10.

46. Bautista LE. Factors associated with initiation of breast-feeding in the Dominican Republic. Rev Panam Salud Publica. 1997;1:200-7.

47. Koosha A, Hashemifesharaki R, Mousavinasab N. Breast-feeding patterns and factors determining exclusive breast-feeding. Singap Med J. 2008;49:1002-6.

48. Hector DJ. Complexities and subtleties in the measurement and reporting of breastfeeding practice. Int Breastfeeding J. 2011;6(1):5.

49. Arimond M, Ruel MT: Progress in developing an infant and child feeding index: An example from the Ethiopia Demographic and Health Survey 2000. Food Consumption and Nutrition Division Discussion Paper. Washington, D. C: International Food Policy Research Institute; 2002.

50. Piwoz EG, Creed de Kanashiro H, Lopez de Romana G, Black RE, Brown KH Potential for misclassification of infants' usual feeding practices using 24hour dietary assessment methods. Nutr J. 1995;125:57-65.

51. Binns CW, Fraser ML, Lee AH, Scott J. Defining exclusive breastfeeding in Australia. J Paediatr Child Health. 2009;45:174-80.

52. Aarts C, Kylberg E, Hörnell A, Hofvander Y, Gebre-Medhin M, Greiner T. How exclusive is exclusive breastfeeding? A comparison of data since birth with current status data. Int J Epidemiol. 2000;29:1041-6.

\section{Publisher's Note}

Springer Nature remains neutral with regard to jurisdictional claims in published maps and institutional affiliations.

Ready to submit your research? Choose BMC and benefit from:

- fast, convenient online submission

- thorough peer review by experienced researchers in your field

- rapid publication on acceptance

- support for research data, including large and complex data types

- gold Open Access which fosters wider collaboration and increased citations

- maximum visibility for your research: over $100 \mathrm{M}$ website views per year

At $\mathrm{BMC}$, research is always in progress.

Learn more biomedcentral.com/submissions 